\title{
Diabetes-associated changes in the fetal insulin/insulin-like growth factor system are organ specific in rats
}

\author{
Verónica White', Alicia Jawerbaum', María B. Mazzucco', Martin Gauster², Gernot Desoye ${ }^{3}$ and Ursula Hiden ${ }^{3}$
}

\begin{abstract}
BACKGROUND: Diabetes in pregnancy affects fetal growth and development. The insulin/insulin-like growth factors (IGF) system comprising insulin, IGF, their receptors, and binding proteins, has been implicated in fetal growth regulation. This study tested the hypothesis that maternal diabetes alters the fetal insulin/IGF system in a tissue-specific manner.
\end{abstract}

METHODS: Wistar rats were rendered diabetic by neonatal administration of streptozotocin and mated with control rats. At day 21 of gestation, the weights of fetuses, placentas, and fetal organs (heart, lung, liver, stomach, intestine, and pancreas) were determined. Maternal and fetal plasma concentrations of insulin, IGF1, and IGF2 were measured by ELISA, and expression of IGF1, IGF2, IGF1R, IGF2R, IR, IGFBP1, BP2, and BP3 in placenta and fetal organs by $\mathrm{qPCR}$.

RESULTS: The well-known increase in fetal growth in this model of mild diabetes is accompanied by elevated insulin and IGF1 levels and alterations of the insulin/IGF system in the fetus and the placenta. These alterations were organ and gene specific. The insulin/IGF system was generally upregulated, especially in the fetal heart, while it was downregulated in fetal lung. CONCLUSION: In our model of mild diabetes, the effect of maternal diabetes on fetal weight and fetal insulin/IGF system expression is organ specific with highly sensitive organs such as lung and heart, and organs that were less affected, such as stomach.

D iabetes in pregnancy, i.e., the fetal exposure to hyperglycemia in utero, has become recognized as a risk factor for immediate adverse pregnancy outcome, and in having longterm effects on mother and offspring. Immediate outcomes include excessive fetal fat accretion as well as congenital malformations, such as cardiac, musco-skeletal, and central nervous system anomalies $(1,2)$. Early evidence in Pima Indians and in animal models has clearly shown that long-term effects of growing in a diabetic environment in utero include a higher risk for the offspring to develop obesity, type 2 diabetes (T2D), the metabolic syndrome, and cardiovascular disease later in life (3). This was confirmed in further studies in which offspring from diabetic pregnancies were followed up into adolescence (4).
One of the well-known effects of the diabetic environment on the offspring is its growth promoting action as reflected by weight increases of the fetus proper and of some fetal tissues $(5,6)$. The insulin/IGF system is a potent regulator of development and growth, and elevated levels of cord blood insulin can be regarded as hallmark of fetal changes in the wake of maternal diabetes $(7,8)$. This system comprises insulin, the insulin-like growth factors-1 (IGF1) and -2 (IGF2), the receptors for insulin (IR), IGF1 (IGF1R) and IGF2 (IGF2R) as well as a range of binding proteins (IGFBP1-6) for both IGFs, which regulate IGF bioavailability by modulating the half-life of IGFs and their site of action (9). Only a small proportion of IGFs circulates in a free form, the bulk is bound to IGFbinding proteins (IGFBPs). Among the six known IGFBPs, IGFBP 1-3 have been comprehensively investigated. The ligands can act locally in a paracrine manner through binding to their cognate receptors. In addition, after secretion in the circulation, they can also exert effects in target tissues different from their site of production and release. Insulin and IGF1 signal through their respective receptors (IR, IGF1R). IGF2 can bind to several receptors: (i) the IGF2R which has been predominantly regarded as a molecular sink for IGF2 thus modulating IGF2 bioavailability, although it might have an independent signaling function. (ii) The IGF1R and (iii) the insulin receptor isoform excluding exon 11 (IR11-) which is mostly expressed in fetal and cancer tissues (10). The IR isoforms are generated by alternative splicing of exon 11 resulting in transcripts either including (IR11+) or excluding (IR11-) exon 11, respectively) (10).

General and tissue-specific knock-out and transgenic overexpression models have clearly established the importance of many of the components of the insulin/IGF system for embryonic growth in mice, and have demonstrated some tissue selectivity of the effects (11). These studies have also boosted our understanding of the significance of each tissue component in fetal development and growth. However, the changes associated with maternal diabetes are more complex, because they affect almost every component of the system studied so far, they interact with the complex diabetes-associated endocrine and metabolic changes beyond the insulin/IGF system, and 
they may differ among organs. Moreover, opportunistic compensation (12) may add to the phenotypes obtained. Therefore, the role of the insulin/IGF system is still unclear.

Studies in human fetuses are not feasible, thus animal models have to be used despite all their limitations for pregnancy studies. Streptozotocin-induced models of diabetes have the advantage that different protocols and strains can be used to generate either mild, moderate, or severe forms of the disease. They also offer the advantage to study the effect of the diabetic environment without the complication of confounding the results by treatment modalities as they have to be used in human $(5,13)$. The neonatal-induced streptozotocin-model of diabetes in the rat has been widely employed $(14,15)$. We have characterized a neonatal streptozotocin-induced mild diabetic model during pregnancy in our laboratory and have demonstrated metabolic derangements and a pro-oxidative and pro-inflammatory intrauterine environment, which alters the embryo, the fetus and the placenta during their development $(15,16)$. This model has maternal glycemia levels of 150$250 \mathrm{mg} / \mathrm{dl}$ and, thus, resembles the levels of hyperglycemia frequently seen in human diabetic pregnancies. Moreover, the model is characterized by impaired maternal glucose and lipid metabolism, as well as placentomegalia and fetal macrosomia (17), typical outcomes of diabetic pregnancies in human $(1,18)$ and is therefore a good model representing diabetes in humans and for studying the regulation of feto-placental growth.

In this study, we tested the hypothesis that the intrauterine environment even of mild forms of diabetes has selective effects on fetal tissues and differently modifies the insulin/IGF system in fetal organs. This would reflect differential sensitivity of the fetal organs to changes in the fetal insulin/IGF system induced by maternal diabetes.

To this end, we measured maternal and fetal serum levels of insulin and IGFs, the weight of the fetus and various fetal organs as well as the expression of the insulin/IGF system in fetal organs.

\section{RESULTS}

\section{Metabolic State}

At term gestation, the diabetic rats showed significantly higher levels of glycemia $(208 \pm 19 \mathrm{mg} / \mathrm{dl})$ than controls $(82 \pm 3 \mathrm{mg} /$ dl, $P<0.001)$. Also, offspring from diabetic rats had higher glycemia levels $(185 \pm 8 \mathrm{mg} / \mathrm{dl})$ than the controls $(44 \pm 4 \mathrm{mg} /$ dl, $P<0.01$ ) (Figure 1a,b). Streptozotocin toxicity to $\beta$ cells caused a reduction of maternal insulin levels by $15 \%$ (controls: $1.35 \pm 0.07$ vs. diabetes: $1.19 \pm 0.05 \mathrm{ng} / \mathrm{ml} ; P<0.05$ ) conforming to the mild model of diabetes employed here. However, fetuses showed more dramatic differences with an increase in insulin by $70 \%(P<0.01)$ (Figure $1 \mathbf{c}, \mathbf{d})$. Comparison of insulin resistance (HOMA-IR) between fetuses from control vs. diabetic rats $(0.98 \pm 0.30$ vs. $5.45 \pm 1.40, P<0.05)$ revealed that fetuses from diabetic rats were insulin resistant.

\section{Offspring and Tissue Weights}

The litter size of diabetic rats was similar to the control group $(11.6 \pm 0.4$ vs. $12.5 \pm 0.4)$. The offspring in the diabetic group a

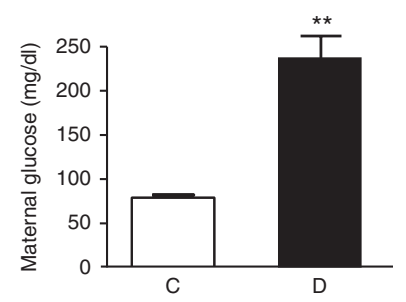

C

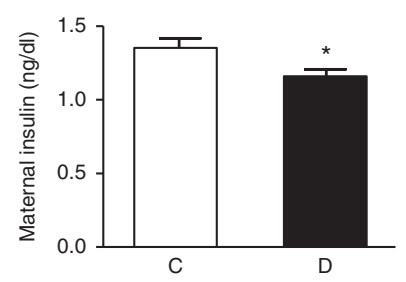

e

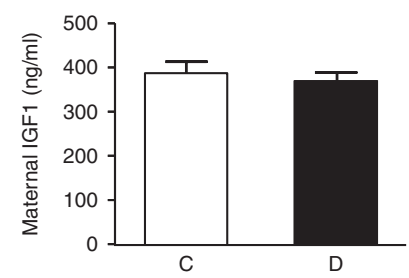

g

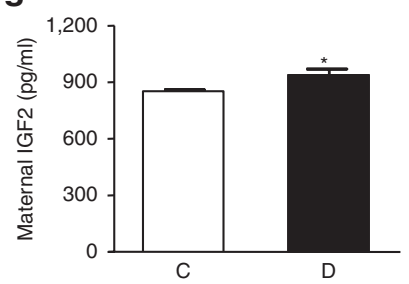

b

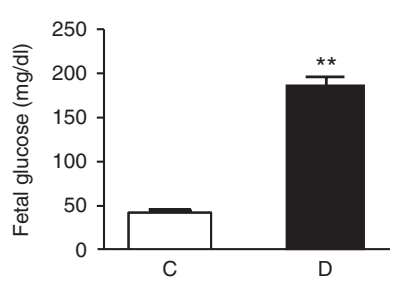

d

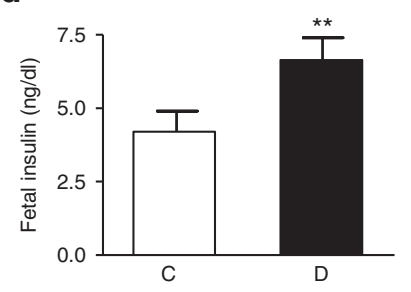

f

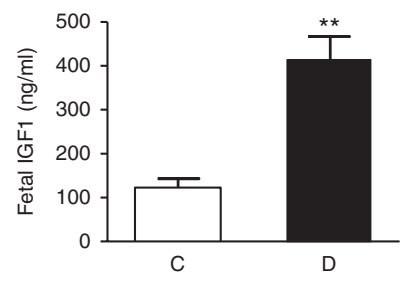

h

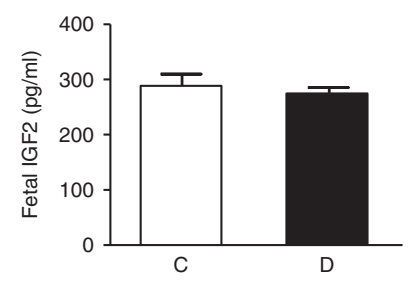

Figure 1 Plasma parameters. Concentrations (mean \pm SEM) of glucose, insulin, IGF1, and IGF2 in the $(\mathbf{a}, \mathbf{c}, \mathbf{e}, \mathbf{g})$ maternal and $(\mathbf{b}, \mathbf{d}, \mathbf{f}, \mathbf{h})$ fetal circulation in control (C, white bars; $N=12)$ and diabetic ( $D$, black bars; $N=11)$ rats. For the measurement of fetal concentrations, plasma from 12 control litters and 11 diabetic litters at day 21 of gestation was pooled. ${ }^{*} P<0.05$, ${ }^{* *} P<0.01$ vs. control.

were heavier than the controls $(P<0.01)$, to which most organs contributed. The placenta was the organ with the strongest weight increase in diabetes that exceeded the weight gain of the fetus. The comparison between fetal and placental weight gain indicates no change in placental efficiency in maternal diabetes as indicated by similar fetal/placental weight ratios as compared to the controls. Most of the fetal organ showed an increase in weight that was proportional to the fetal weight increase; however, fetal lung and placenta were heavier than controls in proportion to the fetal weight increase (Table 1).

\section{Circulating Levels of IGFs}

IGF1 levels were unchanged and free IGF2 levels were $10 \%$ higher $(P<0.05)$ in the diabetic pregnant rats (Figure 1e,g). While circulating levels of IGFs in the mothers were only moderately altered, the fetuses showed profound changes: IGF1 rose by $200 \%$ of the control levels ( $P<0.01$, Figure 1f). Of 
Table 1 Weight (mean \pm SEM) of fetuses and fetal organs (mg) and relative weight changes (\%)

\begin{tabular}{|c|c|c|c|c|}
\hline & & Control & Diabetes & $\begin{array}{c}\text { Relative } \\
\text { change (\%) in } \\
\text { diabetes vs. } \\
\text { control }\end{array}$ \\
\hline \multicolumn{2}{|l|}{ Fetus } & $3,239 \pm 37$ & $3,666 \pm 46^{* *}$ & $+13.2 \pm 1.5$ \\
\hline \multirow[t]{2}{*}{ Placenta } & $\begin{array}{l}\text { Absolute } \\
\text { weight (mg) }\end{array}$ & $562.0 \pm 6.9$ & $683.9 \pm 11.3^{* *}$ & $+21.7 \pm 2.1$ \\
\hline & $\begin{array}{l}\text { Efficiency } \\
\text { (fetal/placental } \\
\text { weight) }\end{array}$ & $5.93 \pm 0.26$ & $5.48 \pm 0.26$ & \\
\hline \multirow[t]{2}{*}{ Liver } & $\begin{array}{l}\text { Absolute } \\
\text { weight (mg) }\end{array}$ & $254.1 \pm 5.2$ & $284.1 \pm 5.2^{* *}$ & $+11.8 \pm 1.5$ \\
\hline & $\begin{array}{l}\% \text { to body } \\
\text { weight }\end{array}$ & $7.72 \pm 0.35$ & $7.72 \pm 0.16$ & \\
\hline \multirow[t]{2}{*}{ Lung } & $\begin{array}{l}\text { Absolute } \\
\text { weight }(\mathrm{mg})\end{array}$ & $94.5 \pm 2.2$ & $110.7 \pm 1.2^{* *}$ & $+17.3 \pm 2.3$ \\
\hline & $\begin{array}{l}\% \text { to body } \\
\text { weight }\end{array}$ & $2.82 \pm 0.13$ & $3.01 \pm 0.13$ & \\
\hline \multirow[t]{2}{*}{ Heart } & $\begin{array}{l}\text { Absolute } \\
\text { weight (mg) }\end{array}$ & $22.4 \pm 0.2$ & $24.1 \pm 0.4^{* *}$ & $+7.7 \pm 1.1$ \\
\hline & $\begin{array}{l}\% \text { to body } \\
\text { weight }\end{array}$ & $0.67 \pm 0.04$ & $0.66 \pm 0.02$ & \\
\hline \multirow[t]{2}{*}{ Pancreas } & $\begin{array}{l}\text { Absolute } \\
\text { weight (mg) }\end{array}$ & $21.2 \pm 0.6$ & $20.8 \pm 0.5$ & $-1.9 \pm 0.2$ \\
\hline & $\begin{array}{l}\% \text { to body } \\
\text { weight }\end{array}$ & $0.64 \pm 0.04$ & $0.58 \pm 0.02$ & \\
\hline \multirow[t]{2}{*}{ Intestine } & $\begin{array}{l}\text { Absolute } \\
\text { weight (mg) }\end{array}$ & $79.3 \pm 1.9$ & $86.0 \pm 1.7^{*}$ & $+8.5 \pm 0.9$ \\
\hline & $\begin{array}{l}\% \text { to body } \\
\text { weight }\end{array}$ & $2.36 \pm 0.09$ & $2.45 \pm 0.08$ & \\
\hline \multirow[t]{2}{*}{ Stomach } & $\begin{array}{l}\text { Absolute } \\
\text { weight (mg) }\end{array}$ & $19.6 \pm 0.5$ & $20.7 \pm 0.5$ & $+5.6 \pm 1.2$ \\
\hline & $\begin{array}{l}\% \text { to body } \\
\text { weight }\end{array}$ & $0.59 \pm 0.03$ & $0.56 \pm 0.05$ & \\
\hline \multicolumn{2}{|c|}{$\begin{array}{l}\text { Total weights of organs } \\
\text { studied }\end{array}$} & 1,053 & 1,230 & $+16.8 \pm 1.5$ \\
\hline \multicolumn{2}{|c|}{$\begin{array}{l}\text { Contribution to total fetal } \\
\text { weight (\%) }\end{array}$} & 32.5 & 33.6 & \\
\hline
\end{tabular}

note, the free fetal IGF2 concentrations were similar between fetuses from controls and diabetic mothers (Figure 1h).

\section{Expression of the Insulin/IGF System in Fetal Organs}

In order to compare insulin/IGF system components between fetal organs of the control group, all expression values were normalized to the expression values in fetal liver, as this is a classical fetal IGF producing and insulin target organ.

In control rats, the placenta was the key fetal tissue to transcribe both IGF1 and IGF2 with 5- and 75-fold expression levels of fetal liver, respectively. Considerable levels of transcripts were also found in fetal stomach, heart and lung. The heart revealed high IGF1 expression levels which were comparable to that of fetal liver. The lung was particularly rich in IGF2 with 40-fold more mRNA than fetal liver (Figure 2a,b).
Different from the ligands (IGF1, IGF2), the IGF and insulin receptors were higher expressed in the liver than placenta. All other tissues showed less receptor expression than liver except the strong IGF2R signal in stomach (Figure 2c-e). Among the IGF binding proteins measured, BP1 was most prominent in stomach and heart. BP2 showed about 170-fold levels in heart than in all other tissues, whereas BP3 transcripts were mostly found in liver and stomach (Figure $\mathbf{2} \mathbf{f}-\mathbf{h}$ ). Lack of sufficient purified RNA precluded measurements of IGFBPs in the lung.

\section{Effect of Diabetes on the Insulin/IGF System in Fetal Organs}

For the analysis of the effect of maternal diabetes on the insulin/IGF system in fetal organs, expression values of the diabetic group were normalized to expression values of the control group for each organ.

Maternal diabetes affected many of the target genes in fetal rat organs, however, with some gene and tissue specificity. The insulin/IGF system of the fetal heart was most susceptible to the diabetic influences, as it was the organ in which almost all the insulin/IGF system components were significantly altered. However, also placenta, fetal liver and fetal lung responded strongly (Figure 3).

The very high control levels of IGF1 and IGF2 transcripts in the placenta relative to other tissues were even augmented in diabetes. However, in the liver, the relative diabetes-associated changes of IGF1 (+2-fold) and IGF2 (+3-fold) were even stronger than in placenta (IGF1 and IGF2: +0.8 -fold)(Figure 3a,b). The fetal heart also showed upregulation of the IGF1 and 2 expression (Figure 3c).

All receptors studied were upregulated by diabetes in the heart, but IR showed the most pronounced effect $(+3$-fold $)$ in stomach (Figure $3 \mathrm{c}, \mathbf{d}$ ). By contrast, in lung the system was depressed in diabetes by reducing IGF1 $(P<0.01)$ and IR $(P<$ $0.05)$ expression as well as by threefold upregulation $(P<0.01)$ of IGF2R (Figure 3e).

IGFBP1 was upregulated in most tissues, with strongest effects in placenta $(+2$-fold $)$, heart $(+2$-fold $)$ and stomach $(+2.3$-fold) (Figure 3a,c,d) IGFBP2 showed the most varied changes: upregulated in liver, unchanged in heart and placenta, and downregulated in stomach (Figure 3a-d) whereas IGFBP3 was upregulated in all tissues, with the strongest effect in liver (+3.4-fold) (Figure 3b). IGFBPs were not measured in fetal lung.

The long isoform of the insulin receptor (IR11+) was the major isoform in liver $(74 \pm 5 \%)$ and heart $(65 \pm 3 \%)$ whereas the short IR11- isoform prevailed in placenta, lung and stomach, with only $29 \pm 1 \%, 35 \pm 3 \%$ and $45 \pm 3 \%$ of IR11+. Diabetes did not significantly alter IR isoform splicing in these organs (Table 2).

\section{DISCUSSION}

This study aimed to analyze changes in the fetal insulin/IGF system associated with mild forms of diabetes, and to identify fetal organs which are particularly sensitive to these changes. The most significant findings were that (i) the growth promoting environment of maternal mild diabetes is associated with 
a

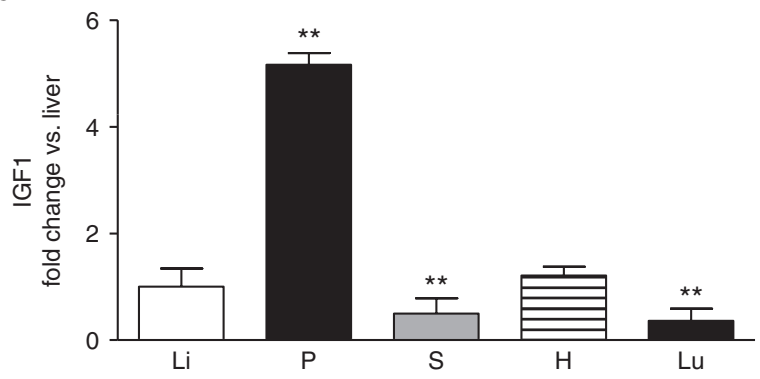

C

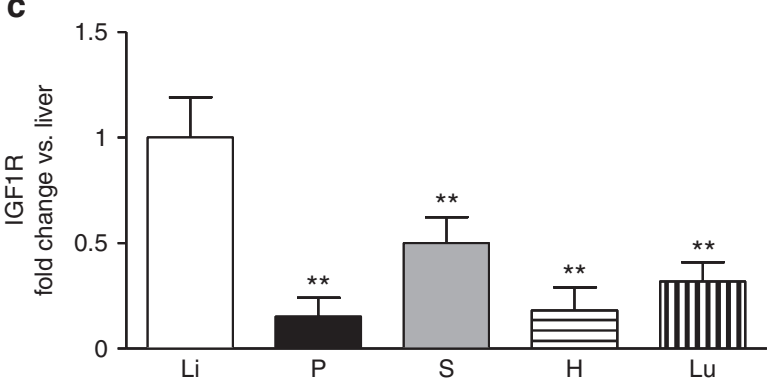

e

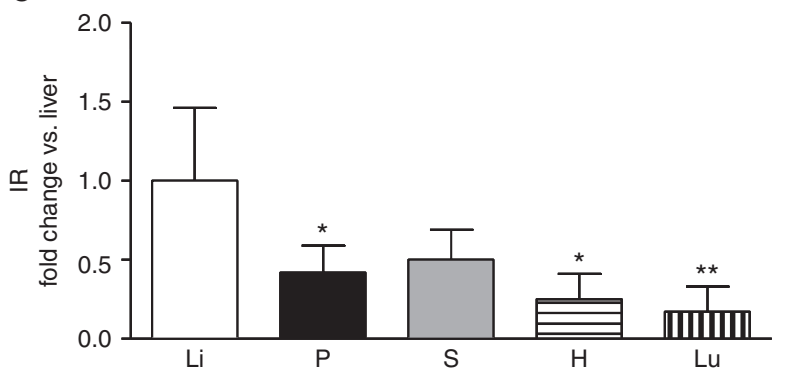

g

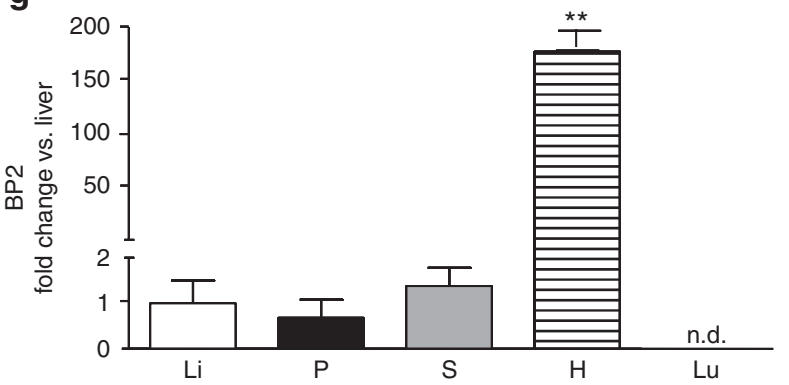

b

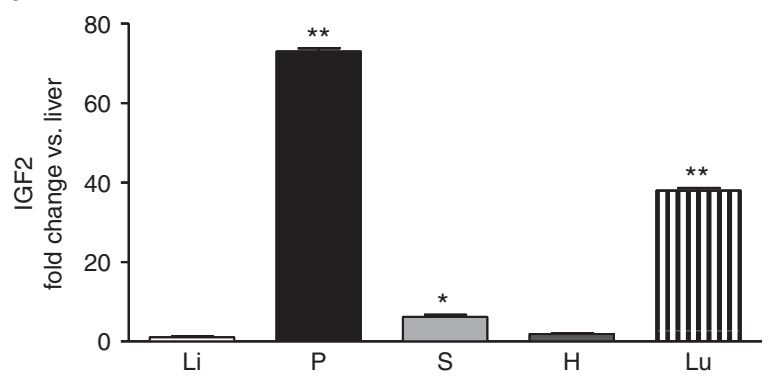

d

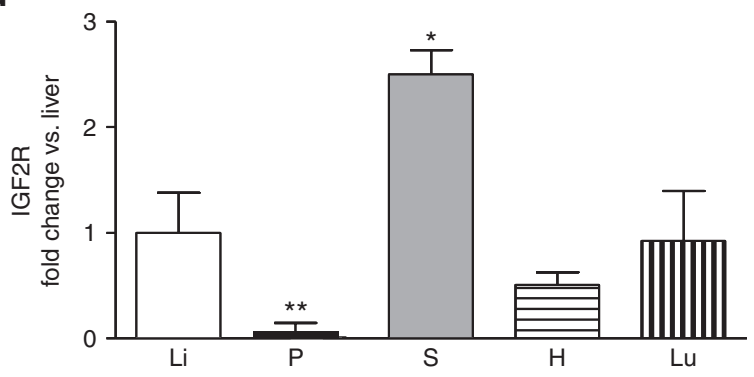

f

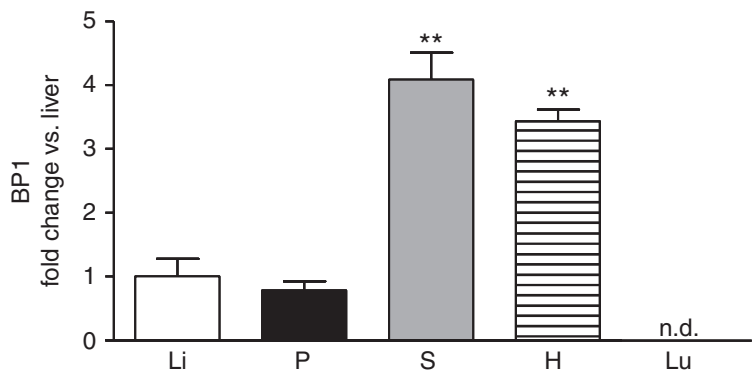

h

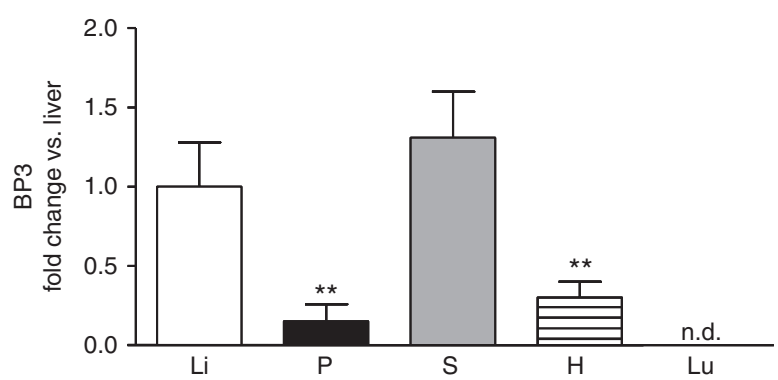

Figure 2 Gene expression in control organs. Gene expression of components of the insulin/IGF system in placenta and fetal organs from normal control rats at day 21 of gestation. Values for (a) IGF1, (b) IGF2, (c) IGF1R, (d) IGF2R, (e) IR, (f) BP1, (g) BP2, and (h) BP3 are presented as fold change (mean $\pm \mathrm{SEM}$ ) in each tissue relative to liver $(=1)$ for each target gene; a total of 12 fetuses, one from each of 12 control dams was measured. Li, liver (white bars); P, placenta (black bars); S, stomach (gray bars); H, heart (vertically hatched); Lu, lung (horizontally hatched); n.d., not determined. ${ }^{*} P<0.05,{ }^{* *} P<0.01$ vs. liver.

organ specific weight increase: Placenta and fetal lung showed a significant weight gain. (ii) Maternal diabetes altered the fetal insulin/IGF system in a complex and organ specific manner. In general, IGFs, receptors and binding proteins were upregulated in fetal organs. Fetal liver IGF expression was most sensitive towards diabetes and responded with the highest upregulation. (iii) The placenta was the organ with the highest expression levels of IGF1 and IGF2, by far exceeding that of all other fetal organs including liver.
The well-known growth promoting effect of the diabetic environment in utero as observed in human pregnancy was also confirmed here in the animal model: hyperinsulinemia and elevated IGF1 levels were paralleled by an increase in fetal body weight. Detailed analysis revealed also an increase in weight of most but not all fetal organs. The weight increase of lung and placenta parallels findings also in human fetuses (19-22).

Of note are the diabetes induced changes in the lung: While growth factors and signaling receptors are increased 

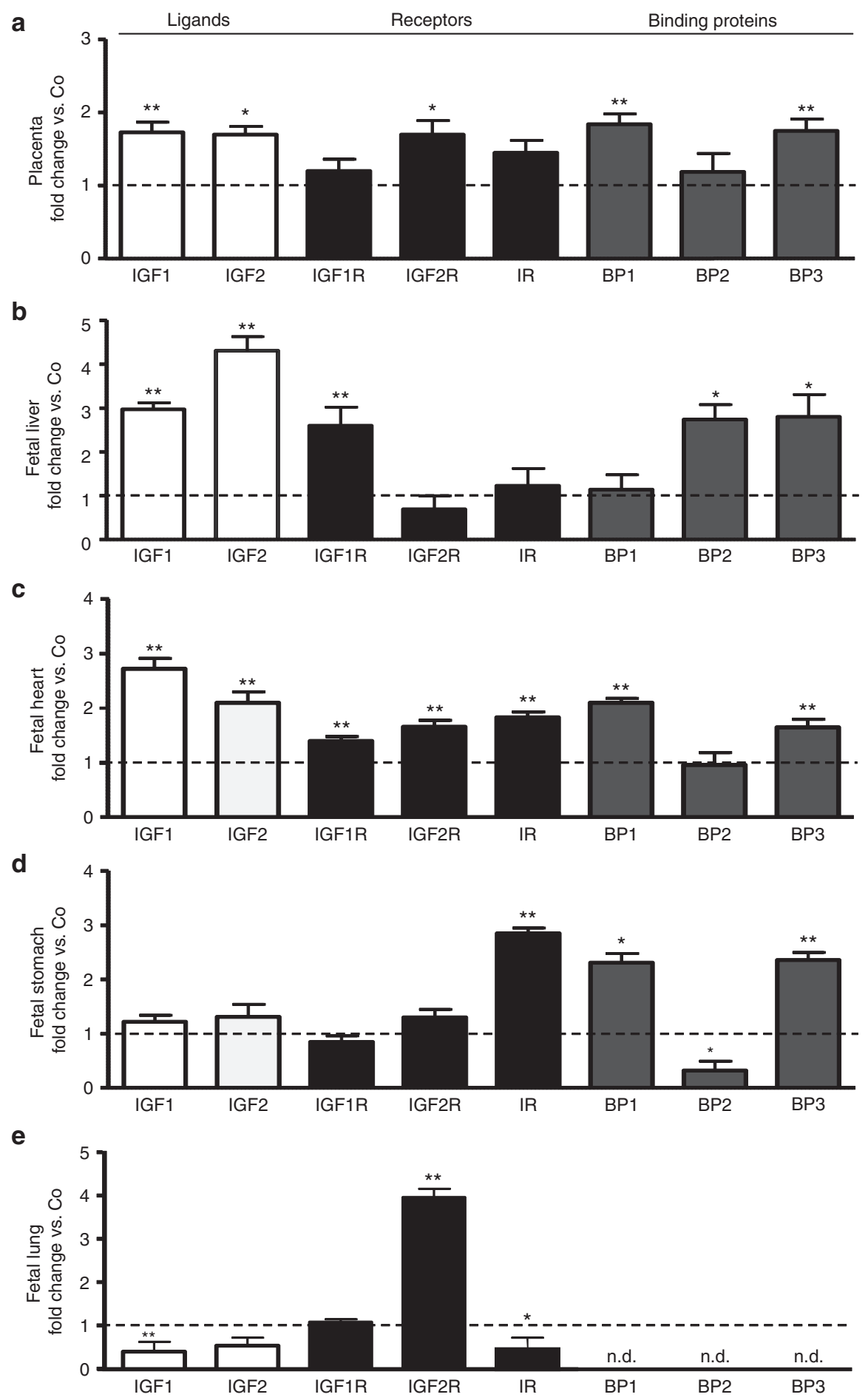

Figure 3 Gene expression, effect of diabetes. Effects of mild maternal diabetes on components of the insulin/IGF system in (a) placenta, (b) liver, (c) heart, (d) stomach, and (e) lung of fetuses from diabetic vs. normal rats at day 21 of gestation. Values are presented as fold change (mean \pm SEM) in maternal diabetes relative to controls (=1) for each target gene and organ. Open bars: IGFs; black bars: receptors; gray bars: IGF binding proteins. One fetus per dam was analyzed resulting in a total of 12 control and 11 diabetic fetuses. Co, control; IGFs, insulin-like growth factors; n.d., not determined. ${ }^{*} P<0.05$, ${ }^{* *} P<0.01$ vs. control.

by maternal diabetes in placenta and other fetal organs, fetal lungs of the diabetic group responded predominantly with a downregulation of IGFs and receptors such as to weaken the mitogenic effects of the growth factors. Only IGF2R serving to clear IGF2 from the circulation with some independent signaling function was upregulated. Lack of enough material precluded measurements of IGFBPs. If this overall effect may be related to the delayed lung maturation with entailing higher risk for respiratory distress syndrome in fetuses of poorly controlled diabetic mothers (20) remains to be studied. However, isolated information obtained from knock out models demonstrates the important role of IGF1 and IGF2 in lung 
Table 2 Prevalence of insulin receptor IR11- (\% of total insulin receptor) in fetal organs from controls (C) and diabetic (D) dams

\begin{tabular}{lcc}
\hline Fetal organ & IR1 $1-(\%)$ in C & IR11- (\%) in D \\
\hline Placenta & $71 \pm 2$ & $67 \pm 4$ \\
Liver & $28 \pm 3$ & $25 \pm 4$ \\
Stomach & $55 \pm 3$ & $63 \pm 3$ \\
Heart & $35 \pm 3$ & $32 \pm 2$ \\
Lung & $65 \pm 1$ & $64 \pm 2$ \\
\hline
\end{tabular}

growth and maturation and in the development of respiratory problems (23). Furthermore, hyperactivation of the insulin signaling pathway has recently been implicated in the pathogenesis of the respiratory distress syndrome in offspring born to diabetic mothers (24).

Classically, the liver is regarded as the main IGF producing organ (25). However, placental expression levels of IGF1 and IGF2 by far exceeded levels of the fetal liver and all other fetal organs analyzed. The fetal heart expressed as much IGF1 as the liver, while fetal lung and stomach expressed IGF2 at higher levels than the liver. Also in the human fetus and similar to the results here, both IGFs are produced at different extrahepatic sites, which change with development $(26,27)$.

The fetal heart has shown the most profound changes in insulin/IGF system components with both IGFs and all receptors upregulated by diabetes.

We are aware that data on further organs known as targets or production sites of the insulin/IGF system, such as pancreas, skeletal muscle, and kidney, would also be of interest. However, in order to obtain the fetal organs as fast as possible to achieve optimal RNA quality, we had to focus and restrict the number of organs to investigate.

A clear limitation of the study is the lack of functional investigations of the receptors for signaling changes associated with diabetes, which is also suggested by the increased HOMA-IR in fetuses after diabetic pregnancies. Recently, we found changes in insulin signaling in the human placenta in diabetes and obesity (28). Also in the rat placenta, experimental diabetes was associated with functional alterations of the IGF1 receptor despite unchanged receptor binding (29). Besides levels and phosphorylation of insulin signaling components, altered insulin receptor splicing has been implicated in diabetes and insulin resistance (30). However, diabetes had no effect on the relative isoform abundance in this model. This extends findings in adult diabetic rats to the prenatal period (31).

This model of diabetes achieved glycemia levels similar to those frequently found in human diabetic pregnancies, and also changes in fetal circulating insulin and IGF1 levels found in this study were also found in diabetic patients (8). However, in human diabetic pregnancies, also cord blood IGF2 levels are higher than in non-diabetic controls (32), likely as a result of fetal hyperglycemia and hyperinsulinemia $(33,34)$. The absence of elevated free fetal IGF2 levels in diabetes despite hyperglycemia and hyperinsulinemia as well as more IGF2 transcripts in fetal liver and placenta may reflect a high proportion of
IGF2 bound to IGFBPs. IGFBPs are also elevated in many fetal organs and IGF2 bound to them could not be detected by the ELISA.

Studies in fetal swine investigating IGF1 mRNA expression in fetal organs indeed showed a similar pattern of changes: Maternal diabetes increased fetal serum insulin and IGF1 and IGF1 mRNA was elevated in fetal liver, placenta, and fetal heart while lung levels were not (35).

Also, outcomes on specific organs identified here are found in human diabetes in pregnancy, i.e., hypertrophy of fetal lung and placenta. This should allow drawing conclusions from the present results to effects of diabetes in human pregnancies, however, with the precautions that always have to be made when using animal models for human disease $(5,36,37)$. One of the differences is that human offspring are born with 12$15 \%$ fat at term of pregnancy and in maternal diabetes, fetus and newborn are characterized by an excessive i.e., over proportional, accumulation of fat $(18,37)$. Rodent fetuses are born with only about $2 \%$ fat, without mature adipocyte differentiation, making extrapolations about diabetes-induced differentiated adipose tissue accumulation impossible.

This study demonstrates that in mild maternal diabetes many of the insulin/IGF components are altered in fetal organs, and insulin and IGF1 also in the fetal circulation. The complexity of the system does not allow direct cause-effect conclusions. Thus, the contribution of each of these changes in the insulin/ IGF system to growth, i.e., weight changes and potential developmental and functional changes in individual organs remains to be established. Concomitantly, fetuses from diabetic rats are insulin resistant, indicating that besides morphological, i.e., weight changes, also profound metabolic effects in the fetuses accompany the diabetic state. Thus, it is obvious that already small metabolic and endocrine perturbations in this model of mild diabetes entail in part profound changes in the insulin/ IGF system.

\section{METHODS}

\section{Animals}

Albino Wistar rats were bred with free access to commercial rat chow (Asociación Cooperativa Argentina, Buenos Aires, Argentina) and tap water and kept at a controlled temperature of $20^{\circ} \mathrm{C}$, with $14 \mathrm{~h} \mathrm{light}$ and $10 \mathrm{~h}$ dark lighting cycles. Diabetes was induced in the 2-d old female rats by subcutaneous injection of a single dose of streptozotocin $(90 \mathrm{mg} / \mathrm{kg})$ diluted in citrate buffer $(0.05 \mathrm{~mol} / \mathrm{l}, \mathrm{pH} 4.5)(14,15)$. Controls were injected with citrate buffer alone. Glycemia of adult diabetic rats (3 mo of age) was measured by the Accu-Chek (Bayer Diagnostics, Buenos Aires, Argentina) reagent strips and a glucometer (Accu-Chek). Eighty percent of rats injected with streptozotocin developed diabetes, 5\% died and 15\% developed glycemia values in between 100 and $150 \mathrm{mg} / \mathrm{dl}$. Adult female diabetic rats with glycemia higher than $150 \mathrm{mg} / \mathrm{dl}$, and control rats with glycemia below $100 \mathrm{mg} /$ $\mathrm{dl}$ were used for the study and mated with healthy males. Pregnancy was confirmed by the presence of sperm cells in vaginal smears at day 1 of gestation. The guidelines for care and use of animals approved by the local institution CICUAL (Institutional Committee for the Care and Use of Laboratory Animals) (permit number 2954/10 and 1494/2013) from the School of Medicine, Buenos Aires University were followed, according to the Principles of Laboratory Animal Care (NIH publication number 85-23, revised 1985, http://grants1.nih. gov/grants/olaw/references/phspol.htm). 


\section{Sample Collection}

Pregnancy was allowed to normally develop until day 21 of gestation, when 12 control and 11 diabetic mothers were $6 \mathrm{~h}$ fasted during their rest period between 6 a.m. and 12 a.m., and anesthetized in a $\mathrm{CO}_{2}$ chamber. After blood was collected with a heparinized (Fada Pharma, Buenos Aires, Argentina) syringe from the abdominal aorta, the animals were sacrificed by cervical dislocation and fetuses and placentas were immediately removed. Fetuses were sacrificed by decapitation and fetal blood was collected. Maternal and fetal plasma were obtained by blood centrifugation, fetal plasma from each litter was pooled and conserved at $-80^{\circ} \mathrm{C}$ for further determinations. Placentas were weighed, immediately fixed in RNAlater (Ambion, Carlsbad, CA) and kept at $-20^{\circ} \mathrm{C}$. Fetuses were weighed and fetal organs were carefully removed under a stereomicroscope using microsurgical dissecting instruments. Fetal organs were weighed and the litter averages were used to calculate the mean weight ratios for all litters. Organs and placentas from two fetuses from each litter were randomly chosen, fixed in RNAlater and kept at $-20^{\circ} \mathrm{C}$.

\section{Blood Analyses}

All assays were run in dupli/triplicate.

Glucose. Maternal and fetal glycemia were measured by a colorimetric enzymatic commercial kit (Wiener labs, Rosario, Argentina).

Insulin. Maternal and fetal plasma insulin levels were measured by a commercial EIA (Mercodia Ultrasensitive Rat Insulin ELISA kit, Uppsala, Sweden), following the company's instructions. Briefly, $25 \mu \mathrm{l}$ of each plasma sample were allowed to interact with the anti-insulin antibody coated on the microplate and with the enzyme conjugate. After $2 \mathrm{~h}$ incubation, the plate was washed and the substrate added. The reaction was stopped after $15 \mathrm{~min}$ and the plate read at $450 \mathrm{~nm}$. Sample insulin concentration was calculated from the calibrator curve. Intra- and interassay coefficients of variation were 4.3 and $9.2 \%$, respectively.

IGF1. Maternal and fetal plasma IGF1 levels were measured by a commercial EIA, IGF1 HS ELISA (Immunodiagnosticsystem, Phoenix), following the company's instructions. In order to measure the total, i.e., bound and free IGF1, maternal and fetal plasma samples were added to a releasing reagent that separates IGF1 from the IGFBPs. Samples, calibrators and controls were allowed to interact with the anti-IGF1 antibody coated on the microplate and with a second, biotinylated anti-IGF1 antibody for $1 \mathrm{~h}$. Then, an avidin-conjugated enzyme was added, excess of enzyme was removed and the substrate was added. After $30 \mathrm{~min}$, the reaction was stopped and the plate read at $450 \mathrm{~nm}$. Intra- and interassay coefficients of variation were 6.4 and $10.5 \%$, respectively.

IGF2. For the measurement of the free circulating IGF2 levels in maternal and fetal plasma, an ELISA (Duoset Mouse IGF 2 ELISA Development) had to be developed according to manufacturer's instructions (R\&D Systems, Abingdon, UK). The ELISA was equally sensitive for mouse and rat IGF2. Briefly, the IGF2 capture antibody $(8 \mu \mathrm{g} / \mathrm{ml})$ was coated onto a 96-well microplate. After blocking and washing, samples were allowed to interact with the primary antibody for $2 \mathrm{~h}$ at $37^{\circ} \mathrm{C}$, followed by washing. Then, a secondary biotinylated detection antibody against IGF2 $(400 \mathrm{ng} / \mathrm{ml})$ was added for $2 \mathrm{~h}$ at RT. After washings, streptavidin-HRP was added for $20 \mathrm{~min}$, followed by a washing step and the addition of the substrate. After 20 min the reaction was stopped and read at $450 \mathrm{~nm}$. Intra- and interassay coefficients of variation were $8.3 \%$ and $12.2 \%$, respectively.

\section{Tissue Analyses}

Semiquantitative analysis of insulin receptor isoforms. Placentas and fetal heart, stomach, lung, and liver that were kept in RNAlater at $-20{ }^{\circ} \mathrm{C}$ were homogenized in Trizol (Life Technologies, Vienna, Austria). RNA was isolated according to manufacturer's instructions and resuspended in RNAase free water. Primers for Insr (forward: CGAGTGCTGCTCATGTCCTA; reverse: GTGGAGGAGATGTTGGGAAA) and Rpl30 (forward: CCATCTTGGCGTCTGATCTT; reverse: TGGCGAGGATAACCA ATTTC) were designed using the public software provided by Primer3 (Bethesda, MD) and purchased from Ingenetix (Vienna, Austria). Primers for IR amplification were designed to bind to exon 10 and 12 . Thus, PCR products differed in size, depending of inclusion (IR11+, 237 bp) or exclusion (IR11-, $201 \mathrm{bp}$ ) of the 36 bp exon 11, and could be distinguished on the $3 \%$ agarose gel. The mRNA of the ribosomal protein L30 (Rpl30) was used as an internal control. All primer-pairs included splicing sites within the amplicon. Total RNA (200 ng) of each sample was used for the one step RT-PCR kit from Qiagen (Hilden, Germany) according to the manufacturer's instructions. The optimum cycle number was determined for RPL30 and INSR in each organ (placenta: 28 and 31 cycles; foetal liver: 29 and 34 cycles; fetal heart: 26 and 29 cycles; fetal lung: 27 and 32 cycles; fetal stomach: 32 and 35 cycles). Each cycle consisted of denaturation at $95^{\circ}$ for $30 \mathrm{~s}$, primer annealing at $58{ }^{\circ} \mathrm{C}$ for $30 \mathrm{~s}$ and extension at $72{ }^{\circ} \mathrm{C}$ for $30 \mathrm{~s}$. PCR-products were electrophoresed on $3 \%$ agarose gels. Images were documented with the Eagle-Eye system Stratagene (Santaclara, CA) and quantified with the AlphaDigiDoc 1000 (Alpha Innotech, San Leandro, CA) software.

Real time quantitative PCR. cDNA was synthesized incubating $1 \mu \mathrm{g}$ of extracted total RNA in a first-strand buffer containing $200 \mathrm{U}$ of MMLV enzyme (Promega, Sunnyvale, CA), $7.5 \mathrm{mmol} / 1$ of random primers hexameres (Promega) and $0.5 \mathrm{mmol} / \mathrm{l}$ of each dNTP (Invitrogen, Carlsbad CA). The reaction mix was incubated at $37^{\circ} \mathrm{C}$ for $45 \mathrm{~min}$, followed by $15 \mathrm{~min}$ at $45^{\circ} \mathrm{C}$ and $20 \mathrm{~min}$ at $70{ }^{\circ} \mathrm{C}$. Gene expression assays for Rpl30 (Rn00321148_g1), Igf1 (Rn99999087_m1), Igf2 (Rn01454518_m1), Igf1r (Rn01477918_m1), Igf2r (Rn01636937_m1), Insr (Rn01637243_ $\mathrm{m} 1), \operatorname{Igfbp} 1$ (Rn01452798_m1), Igfbp2 (Rn00565473_m1), and Igfbp3 (Rn01401281_m1) and the TaqMan Universal Master mix II were purchased from Applied Biosystems (Carlsbad CA) and the methodology followed according to the manufacturer's instructions. The ABI Prism 7900 sequence detection system (Applied Biosystems) PCR cycling conditions were as follows: initial denaturation at $95^{\circ} \mathrm{C}$ for $10 \mathrm{~min}$, followed by 40 cycles at $94^{\circ} \mathrm{C}$ for $30 \mathrm{~s}, 60^{\circ} \mathrm{C}$ for $15 \mathrm{~s}$, and $72{ }^{\circ} \mathrm{C}$ for $30 \mathrm{~s}$, and a 10 min terminal incubation at $72^{\circ} \mathrm{C}$. Sequence Detector Software (SDS version 1.6.3; Applied Biosystems) was used to extract the PCR data and threshold lines were chosen automatically. The data were then exported to Excel software for further analyses. Rpl30 expression was used as an internal expression control, because it did not vary between groups. Gene expression was analyzed using the $2^{-\Delta \Delta \mathrm{Ct}}$ method (38). To calculate the fold change, $\Delta \mathrm{Ct}$ values of all diabetic samples were related to the mean values of the controls which were considered to be 1. Statistics used the $\Delta \mathrm{Ct}$ values.

\section{Statistical Analysis}

Relative differences between samples were analyzed by Student's $t$-test or by analysis of variance with Bonferroni's post hoc test. Differences were considered statistically significant with a $P$ value of $<0.05$.

\section{ACKNOWLEDGMENTS}

The authors thank Romina Higa and Nora Martinez for their valuable contribution in sample preparations and Susanne Kopp and Heidi Miedl for their support with the real-time PCR analyses.

\section{STATEMENT OF FINANCIAL SUPPORT}

This study was supported by a grant from the Argentine National Agency for the Promotion of Science and Technology (ANPCyT) and the Scientific and Technology Project of Investigation (PICT 2010 0034) to A.J. V.W. was supported by an Ernst Mach Fellowship of the Austrian Agency for International Cooperation in Education and Research (OEAD). Moreover, a bilateral grant by the OEAD (AR13/2011 to U.H.) and the Science and Technology Ministry (MINCyT), Argentina (AU1017 to V.W.), supported collaboration between the laboratories.

Disclosure: The authors declare no conflict of interest. 


\section{REFERENCES}

1. Schaefer-Graf UM, Buchanan TA, Xiang A, Songster G, Montoro M, Kjos SL. Patterns of congenital anomalies and relationship to initial maternal fasting glucose levels in pregnancies complicated by type 2 and gestational diabetes. Am J Obstet Gynecol 2000;182:313-20.

2. Wentzel P, Gäreskog M, Eriksson UJ. Decreased cardiac glutathione peroxidase levels and enhanced mandibular apoptosis in malformed embryos of diabetic rats. Diabetes 2008;57:3344-52.

3. Ryan EA, Liu D, BellRC, FinegoodDT, Crawford J.Long-term consequencesin offspring of diabetes in pregnancy: studies with syngeneic islet-transplanted streptozotocin-diabetic rats. Endocrinology 1995;136:5587-92.

4. HAPO Study Cooperative Research Group. Hyperglycemia and Adverse Pregnancy Outcome (HAPO) Study: associations with neonatal anthropometrics. Diabetes 2009;58:453-9.

5. Jawerbaum A, White V. Animal models in diabetes and pregnancy. Endocr Rev 2010;31:680-701.

6. Taricco E, Radaelli T, Nobile de Santis MS, Cetin I. Foetal and placental weights in relation to maternal characteristics in gestational diabetes. Placenta 2003;24:343-7.

7. Hiden U, Glitzner E, Hartmann M, Desoye G. Insulin and the IGF system in the human placenta of normal and diabetic pregnancies. J Anat 2009;215:60-8.

8. Lindsay RS, Westgate JA, Beattie J, et al. Inverse changes in fetal insulin-like growth factor (IGF)-1 and IGF binding protein-1 in association with higher birth weight in maternal diabetes. Clin Endocrinol (Oxf) 2007;66:322-8.

9. Schneider MR, Lahm H, Wu M, Hoeflich A, Wolf E. Transgenic mouse models for studying the functions of insulin-like growth factor-binding proteins. FASEB J 2000;14:629-40.

10. Frasca F, Pandini G, Scalia P, et al. Insulin receptor isoform A, a newly recognized, high-affinity insulin-like growth factor II receptor in fetal and cancer cells. Mol Cell Biol 1999;19:3278-88.

11. Efstratiadis A. Genetics of mouse growth. Int J Dev Biol 1998;42:955-76.

12. Shafrir E. Contribution of animal models to the research of the causes of diabetes. World J Diabetes 2010;1:137-40.

13. López-Soldado I, Herrera E. Different diabetogenic response to moderate doses of streptozotocin in pregnant rats, and its long-term consequences in the offspring. Exp Diabesity Res 2003;4:107-18.

14. Portha B, Blondel O, Serradas $\mathrm{P}$, et al. The rat models of non-insulin dependent diabetes induced by neonatal streptozotocin. Diabete Metab 1989;15:61-75.

15. White V, Capobianco E, Higa R, et al. Increased nitration and diminished activity of copper/zinc superoxide dismutase in placentas from diabetic rats. Free Radic Res 2010;44:1407-15.

16. Martínez N, White V, Kurtz M, Higa R, Capobianco E, Jawerbaum A Activation of the nuclear receptor PPARa regulates lipid metabolism in foetal liver from diabetic rats: implications in diabetes-induced foetal overgrowth. Diabetes Metab Res Rev 2011;27:35-46.

17. Martínez N, Capobianco E, White V, Pustovrh MC, Higa R, Jawerbaum A. Peroxisome proliferator-activated receptor alpha activation regulates lipid metabolism in the feto-placental unit from diabetic rats. Reproduction 2008;136:95-103.

18. Hammami M, Walters JC, Hockman EM, Koo WW. Disproportionate alterations in body composition of large for gestational age neonates. J Pediatr 2001;138:817-21.

19. Mirghani H, Zayed R, Thomas L, Agarwal M. Gestational diabetes mellitus: fetal liver length measurements between 21 and 24 weeks' gestation. J Clin Ultrasound 2007;35:34-7.

20. Bourbon JR, Farrell PM. Fetal lung development in the diabetic pregnancy. Pediatr Res 1985;19:253-67.
21. Kozák-Bárány A, Jokinen E, Kero P, Tuominen J, Rönnemaa T, Välimäki I. Impaired left ventricular diastolic function in newborn infants of mothers with pregestational or gestational diabetes with good glycemic control. Early Hum Dev 2004;77:13-22.

22. Capobianco E, Martínez N, Fornes D, et al. PPAR activation as a regulator of lipid metabolism, nitric oxide production and lipid peroxidation in the placenta from type 2 diabetic patients. Mol Cell Endocrinol 2013;377:7-15.

23. Ludwig T, Eggenschwiler J, Fisher P, D'Ercole AJ, Davenport ML, Efstratiadis A. Mouse mutants lacking the type 2 IGF receptor (IGF2R) are rescued from perinatal lethality in Igf2 and Igf1r null backgrounds. Dev Biol 1996;177:517-35.

24. Ikeda H, Shiojima I, Oka T, et al. Increased Akt-mTOR signaling in lung epithelium is associated with respiratory distress syndrome in mice. Mol Cell Biol 2011;31:1054-65.

25. Norstedt G, Levinovitz A, Möller C, Eriksson LC, Andersson G. Expression of insulin-like growth factor I (IGF-I) and IGF-II mRNA during hepatic development, proliferation and carcinogenesis in the rat. Carcinogenesis 1988;9:209-13.

26. Hill DJ. Relative abundance and molecular size of immunoreactive insulin-like growth factors I and II in human fetal tissues. Early Hum Dev 1990;21:49-58.

27. Han VK, Lund PK, Lee DC, D'Ercole AJ. Expression of somatomedin/ insulin-like growth factor messenger ribonucleic acids in the human fetus: identification, characterization, and tissue distribution. J Clin Endocrinol Metab 1988;66:422-9.

28. Colomiere M, Permezel M, Riley C, Desoye G, Lappas M. Defective insulin signaling in placenta from pregnancies complicated by gestational diabetes mellitus. Eur J Endocrinol 2009;160:567-78.

29. Hauguel-de Mouzon S, Louizeau M, Girard J. Functional alterations of type I insulin-like growth factor receptor in placenta of diabetic rats. Biochem J 1992;288 (Pt 1):273-9.

30. Sesti G, Federici M, Lauro D, Sbraccia P, Lauro R. Molecular mechanism of insulin resistance in type 2 diabetes mellitus: role of the insulin receptor variant forms. Diabetes Metab Res Rev 2001;17:363-73.

31. Vidal H, Auboeuf D, Beylot M, Riou JP. Regulation of insulin receptor mRNA splicing in rat tissues. Effect of fasting, aging, and diabetes. Diabetes 1995;44:1196-201.

32. Yan-Jun L, Tsushima T, Minei S, et al. Insulin-like growth factors (IGFs) and IGF-binding proteins (IGFBP-1, -2 and -3) in diabetic pregnancy: relationship to macrosomia. Endocr J 1996;43:221-31.

33. Goya L, de la Puente A, Ramos S, et al. Regulation of IGF-I and -II by insulin in primary cultures of fetal rat hepatocytes. Endocrinology 2001;142:5089-96.

34. Goya L, de la Puente A, Ramos S, Martín MA, Escrivá F, PascualLeone AM. Regulation of insulin-like growth factor-I and -II by glucose in primary cultures of fetal rat hepatocytes. J Biol Chem 1999;274:24633-40.

35. Ramsay TG, Wolverton CK, Steele NC. Alteration in IGF-I mRNA content of fetal swine tissues in response to maternal diabetes. Am J Physiol 1994;267(5 Pt 2):R1391-6.

36. Herrera E, Ortega-Senovilla H. Disturbances in lipid metabolism in diabetic pregnancy - Are these the cause of the problem? Best Pract Res Clin Endocrinol Metab 2010;24:515-25.

37. Ehrenberg HM, Huston-Presley L, Catalano PM. The influence of obesity and gestational diabetes mellitus on accretion and the distribution of adipose tissue in pregnancy. Am J Obstet Gynecol 2003;189:944-8.

38. Livak KJ, Schmittgen TD. Analysis of relative gene expression data using real-time quantitative PCR and the 2(-Delta Delta C(T)) Method. Methods 2001;25:402-8. 